\title{
Theranostics and contrast agents for magnetic resonance imaging
}

\author{
Yohan Jeong, Hee Sook Hwang and Kun $\mathrm{Na}^{*}$
}

\begin{abstract}
Background: Magnetic resonance imaging is one of the diagnostic tools that uses magnetic particles as contrast agents. It is noninvasive methodology which provides excellent spatial resolution. Although magnetic resonance imaging offers great temporal and spatial resolution and rapid in vivo images acquisition, it is less sensitive than other methodologies for small tissue lesions, molecular activity or cellular activities. Thus, there is a desire to develop contrast agents with higher efficiency. Contrast agents are known to shorten both T1 and T2. Gadolinium based contrast agents are examples of T1 agents and iron oxide contrast agents are examples of T2 agents. In order to develop high relaxivity agents, gadolinium or iron oxide-based contrast agents can be synthesized via conjugation with targeting ligands or functional moiety for specific interaction and achieve accumulation of contrast agents at disease sites.

Main body: This review discusses the principles of magnetic resonance imaging and recent efforts focused on specificity of contrast agents on specific organs such as liver, blood, lymph nodes, atherosclerotic plaque, and tumor. Furthermore, we will discuss the combination of theranostic such as contrast agent and drug, contrast agent and thermal therapy, contrast agent and photodynamic therapy, and neutron capture therapy, which can provide for cancer diagnosis and therapeutics.

Conclusion: These applications of magnetic resonance contrast agents demonstrate the usefulness of theranostic agents for diagnosis and treatment.
\end{abstract}

Keywords: Magnetic resonance imaging, Contrast agent, High relaxivity, Targeting

\section{Background}

Since X-rays were discovered by W.C. Roentgen, medical imaging techniques have been contributed the accurate diagnosis [1]. There are a lot of medical imaging techniques that have been developed over 100 years including magnetic resonance imaging (MRI), computed tomography $(\mathrm{CT})$, gamma ray imaging, and ultrasound for accurate diagnosis (Table 1).

Each imaging technique has its advantages and disadvantages, and some imaging techniques are more adaptable than others for specific diagnosis. After medical images have been obtained by various medical imaging tools, they are interpreted by radiologist for

\footnotetext{
* Correspondence: kna6997@catholic.ac.kr

Department of Biotechnology, Center for Photomedicine, The Catholic University of Korea, 43 Jibong-ro, Wonmi-gu, Bucheon-si, Gyeonggi do 14662, South Korea
}

effective treatment and disease management. For assisting radiologists' interpretation, contrast agents (CAs) have been developed for enhancing contrast effect of abnormalities such as cancer [2], edema [3], stroke [4], and fracture [5].

Recently, there have been growing interest in the combination of contrast and therapy. Theranostic is a new field of medicine which combines diagnosis and targeted therapy as a single agent [6]. Theranostic agents provide imaging as well as therapy at the same time. These features of theranostic agents offer synergetic advantages in comparison to traditional CAs that are used only to visualize the inside of the body. In order to increase the efficiency of the theranostic agent, it is necessary to increase the contrast effect at target site or to achieve their desired therapeutic effect. To increase the target specific imaging, various methods have been applied on theranostic agents. Targeting antibodies [7], peptides [8], aptamers [9, 10], siRNA [11], pH-sensitive 
Table 1 Imaging technique for diagnosis

\begin{tabular}{|c|c|c|c|c|c|c|}
\hline Imaging modality & Type of probe & Sensitivity & Spatial resolution & Advantages & Disadvantages & Reference \\
\hline MRI & $\begin{array}{l}\mathrm{Gd}, \mathrm{Mn}, \mathrm{Ln} \text {, Iron oxide, } \\
\text { Iron platinum }\end{array}$ & Low & $25-100 \mu m$ & $\begin{array}{l}\text { No radiation } \\
\text { High resolution (soft tissue) }\end{array}$ & $\begin{array}{l}\text { Slow scan } \\
\text { High cost } \\
\text { Noise }\end{array}$ & [109-111] \\
\hline$X$-ray, CT & I, Au, Bi, Xe & Low & $20-100 \mu \mathrm{m}$ & $\begin{array}{l}\text { Low cost } \\
\text { High resolution } \\
\text { (bone fractures) }\end{array}$ & Radiation & {$[112,113]$} \\
\hline Gamma ray & $\begin{array}{l}\text { PET (18F, 68Ga) } \\
\text { SPECT (99mTC, } 111 \mathrm{ln}, 177 \mathrm{Lu})\end{array}$ & High & $1-2 \mathrm{~mm}$ & $\begin{array}{l}\text { High sensitive } \\
\text { High resolution } \\
\text { (biological processes) } \\
\text { Less noise }\end{array}$ & $\begin{array}{l}\text { High cost } \\
\text { Radiation }\end{array}$ & {$[114,115]$} \\
\hline Ultrasound & Microbubbles & low & $50-500 \mu \mathrm{m}$ & $\begin{array}{l}\text { No radiation } \\
\text { Fast scan } \\
\text { Non-invasive } \\
\text { Ease of procedure } \\
\text { Low cost }\end{array}$ & Low resolution & [116] \\
\hline
\end{tabular}

polymers [12], temperature-sensitive polymers [13], catalyst-responsive polymers [14], light sensitive polymers [15], ultrasound sensitive polymers [16], and magnetic stimuli polymers have been investigated to enhance contrast effect at target sites. Moreover, to enhance the therapeutic efficacy, various treatment methods have been developed for various types of disease, such as chemotherapy, radiotherapy, nucleic acid therapy, phototherapy, and hyperthermia treatment.

MRI is a scanning technique based on the nuclear magnetic resonance and provides images of the inside of the body. MRI is a non-invasive, non-radiation, tomographic imaging modality that offers good resolution of soft tissue such as brain [17], heart [18], eyes [19], ligaments [20], and cartilage [21]. In addition, MRI provides high resolution images of blood vessels and organs. MRI technology is based on the manipulation of the inherent nuclear magnetic moment of endogenous nuclei. More than $60 \%$ of body weight is made of water, and the atoms of hydrogen consists of a nucleus with one electron going around it. In the absence of external magnetic field, spins of electrons are randomly aligned. However, when electrons are placed under a strong magnetic field, spins tend to align with or against the applied magnetic field, producing a net bulk magnetization aligned with the direction of applied magnetic field [22]. Then radio-frequency (RF) pulse is applied perpendicular to magnetic field where the RF pulse is produced by driving electrical currents through RF-transmit coils and generates a net magnetic moment of the nuclei. When RF pulse is removed, the nuclei is aligned to original magnetic field. During realignment, the nuclei is aligned parallel to magnetic field. This phenomenon is referred to as relaxation, and the nuclei loses energy by emitting their own RF signals. These signals are measured by a conductive field coil that is placed around the object being imaged. These signals are reconstructed into a 3-dimentional MR image through a computer program.

MR images are divided into $\mathrm{T} 1$-weighted and T2-weighted images. T1 decay is defined as the time after RF pulse needed for the longitudinal magnetization recover to $63 \%$ of ground state of main magnetic field of MRI scanner. T2 decay is defined as the time after RF pulse needed for the exponential loss of transvers magnetization decrease to $37 \%$ of excited state of applied magnetization [23]. In the presence of MR CAs, the relaxation times of surrounding water protons nearby CAs are shortened, increase the signal intensity creating a positive contrast effect [24]. CA is divided into T1-weighted CA, T2-weighted CA, and T1/T2 dual CA. T1-weighted CAs shorten $\mathrm{T} 1$ relaxation time to maximize its $\mathrm{T} 1$ contrast effect that results in a brightening of the MR image [25]. T1 CAs are usually made from lanthanide gadolinium, transition metal manganese, and dysprosium. T2-weighted CAs shorten T2 relaxation time to maximize its $\mathrm{T} 2$ contrast effect that results in a darkening of the MR image. T2 CAs are usually made from superparamagnetic iron oxide (SPIO) and superparamagnetic iron platinum (SPIP). Unlike other imaging tools, MR contrast enhancement is affected by various factors such as chemical exchange with water proton, tumbling time, electron spin state, distance between two dipoles, chemical shift, metal ions, and relative $\mathrm{CA}$ concentration on region of interest [24, 26-28]. Because of these factors, various attempts have been applied to enhance contrast effect on specific target regions and combine therapy with diagnosis. Table 2 shows the conventional CA for MR imaging for diagnosis.

In this review, we will discuss highly target specific MR CAs that show therapeutic efficacy and imaging, and theranostic agents that combined with MRI agent and treatment including region specific MRI agents, 
Table 2 Conventional MR contrast agent for diagnosis

\begin{tabular}{|c|c|c|c|c|c|}
\hline & Main material & Name of compound & Trade name & Target organ & Reference \\
\hline \multirow[t]{13}{*}{$\mathrm{T} 1$} & \multirow[t]{13}{*}{ Gadolinium } & gadoxetate & Primovist & Liver & {$[117]$} \\
\hline & & gadoterate & Dotarem, Clariscan & Brain and spine & [118] \\
\hline & & gadodiamide & Omniscan & Abnormal vascularity & [119] \\
\hline & & gadobenate & MultiHance & Liver & [120] \\
\hline & & gadopentetate & Magnevist & Glioma & [121] \\
\hline & & gadoteridol & ProHance & Brain and spine & [122] \\
\hline & & gadoversetamide & OptiMARK & Brain, spine, and liver & {$[123]$} \\
\hline & & gadobutrol & Gadovist or Gadavist & Angiography & [124] \\
\hline & & gadopentetic acid dimeglumine & Magnetol & Abnormal vascularity & {$[125]$} \\
\hline & & Albumin-binding gadolinium complexes gadofosveset & Ablavar or Vasovist & Angiography & {$[126]$} \\
\hline & & gadocoletic acid & gadocoletic acid & Angiography & [43] \\
\hline & & gadomelitol & gadomelitol & Angiography & [127] \\
\hline & & gadoteric acid & Clariscan & Brain and spine & {$[128]$} \\
\hline \multirow[t]{4}{*}{$\mathrm{T} 2$} & \multirow[t]{4}{*}{ Iron oxide } & Iron oxide & Feridex I.V & Reticuloendothelial system & [129] \\
\hline & & Iron oxide & Lumirem & Gastrointestinal tract & [130] \\
\hline & & Iron oxide & Sinerem & Lymph nodes & [131] \\
\hline & & Iron oxide & Resovist & Reticuloendothelial system & [132] \\
\hline
\end{tabular}

drug loading MRI agents, hyperthermal MRI agents, and neutron capture MRI agents. In addition, their applications will be discussed in this review.

\section{Region specific MRI contrast agent \\ Liver}

The detection of the hepatic lesion during MR imaging of the liver is clinically important for evaluation of liver metastases, since benign and malignant lesions may coexist [29]. Thus, the need of CAs that enhanced liver MR imaging is critical. According to Yim et al., pullulan-conjugated gadolinium diethylene triamine pentaacetate (Gd-DTPA-Pullulan) is designed as a hepatocyte-specific CA (Fig. 1) [30]. Gd-DTPA-Pullulan has a specific binding affinity for asialoglycoprotein receptor that are highly expressed on the membrane of hepatocytes. In vivo MR study demonstrated that intravenous administration of Gd-DTPA-Pullulan highly accumulated in the liver and showed a higher contrast intensity in liver than controls, as well as providing discriminative hepatic imaging (Fig. 2).

Mangafodipir trisodium is a manganese $(\mathrm{Mn})$ chelate which is a MR CA for hepatobiliary system. It is a paramagnetic complex that is metabolized by dephosphorylation and changes to manganese dipyridoxyl monophosphate (Mn-DPMP) and manganese dipyridoxyl ethylenediamine (Mn-PLED) [31]. Mangafodipir trisodium release $\mathrm{Mn}^{2+}$ ions and ions are bound by alpha2-macroglobulin and transported to the liver. Mangafodipir trisodium shows greater $\mathrm{T} 1$ relaxivity in liver tissue than that of gadolinium because of the intracellular uptake of $\mathrm{Mn}^{2+}$ ions [32]. After $30 \mathrm{~min}$ of IV injection in rat, $13 \%$ is present in the liver. $12-20 \mathrm{mg}$ manganese is presented in human body; thus, administration of mangafodipir does not show acute or subchronic toxicity [32]. The safe dosage of mangafodipir is $5 \mu \mathrm{mol} \mathrm{kg}{ }^{-1}$ body weight [33].

Gadobenate dimeglumine is an active ingredient of MultiHance which is used for IV injection for MR imaging of focal liver disease. It is an octadenate chelate of the paramagnetic ion gadolinium. Gadobenate dimeglumine distributes extracellular fluid space and selectively taken up by hepatocytes [34]. In the liver, increased intracellular viscosity within the hepatocytes allows a higher relaxivity about $20 \mathrm{mmol}^{-1} \mathrm{~s}^{-1}[35,36]$.

Gd-Ethoxybenzyl-DTPA (Gd-EOB-DTPA) is a hepatobiliary $\mathrm{CA}$ with hepatocellular uptake via the anionic-transporter protein [37]. A T1-relaxivity in water at $0.47 \mathrm{~T}$ is $4.9 \mathrm{mM}^{-1} \mathrm{~s}^{-1}$, which is comparable to

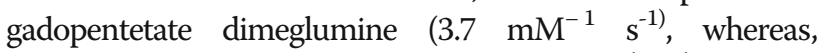
T1-relaxivity in human plasma is $\mathrm{R} 18.2 \mathrm{mM}^{-1} \mathrm{~s}^{-1}$, which is higher than gadopentetate dimeglumine (R1 $\left.5 \mathrm{mM}^{-1} \mathrm{~s}^{-1}\right)$. A possible reason might be due to greater degree of protein binding compare to that of gadobenate dimeglumine [38].

\section{Blood-pool contrast agents (BPCA)}

Natural macromolecule-derived blood-pool CAs include Gd-based MRI CAs, Gd-DTPA covalently linked to proteins such as albumin, IgG, fibrinogen, inulin. Among proteins, albumin conjugated to Gd-DTPA is the most studied and the relaxivity at $0.25 \mathrm{~T}$ is $14.9 \mathrm{mM}^{-1} \mathrm{~s}^{-1}$ 


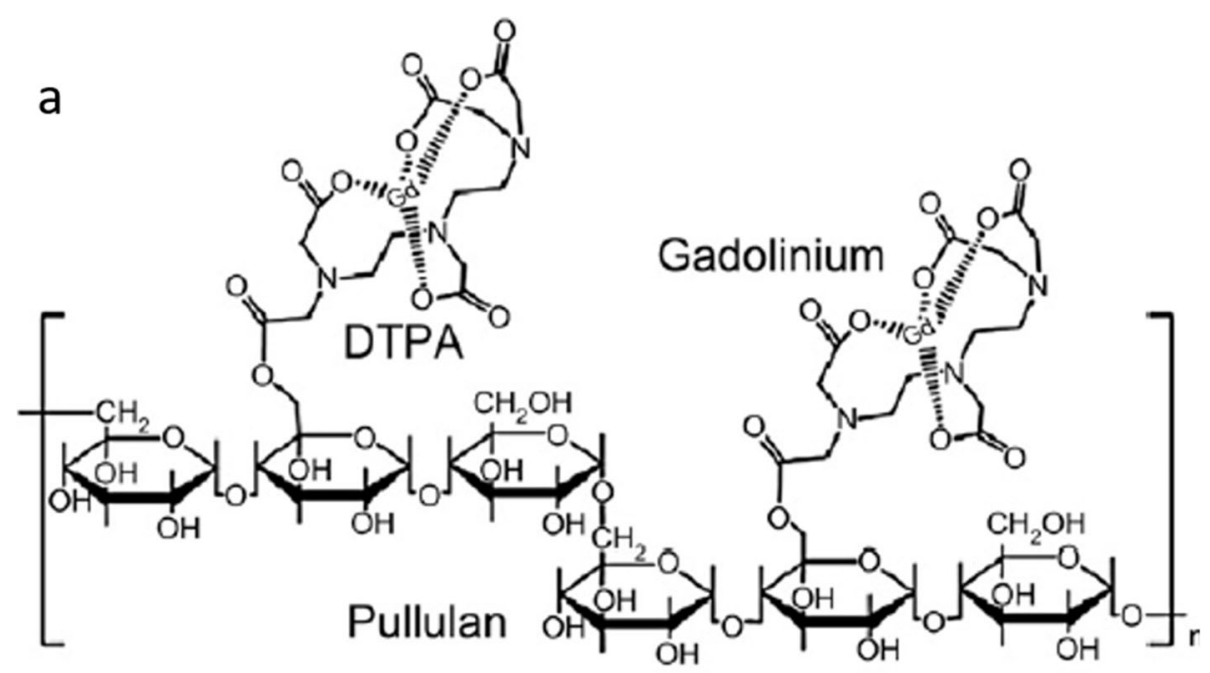

\section{Gd-DTPA-pullulan}
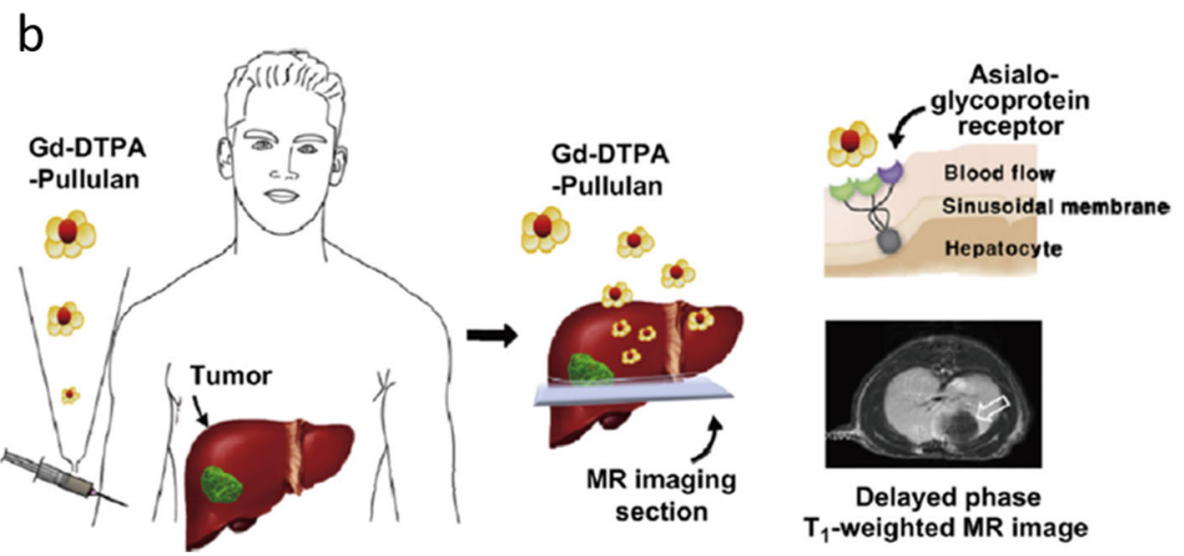

Fig. 1 a A chemical structure of Gd-DTPA-Pullulan. b A schematic illustration of Gd-DTPA-Pullulan as a hepatocyte-specific MR agent [30]

which is higher than the other clinically approved agents [39]. However, albumin-(Gd-DTPA)x has a limitation to the intravascular space, slow elimination, Gd association, and immunogenicity limits the use to blood-pool CA [39].

Targeted blood-pool CAs are designed to localize a specific cell or tissue which include monoclonal antibody conjugates angiogenesis biomarkers, monoclonal antibody LM609 specific to $\alpha_{\mathrm{v}} \beta_{3}$ integrin-targeted, a marker of angiogenic blood vessels. Winter et al. demonstrated that targeted nanoparticles are bound to $\alpha_{\mathrm{v}} \beta_{3}$ integrin epitopes on the aortic wall and delayed contrast enhancement of the vessel wall; thus, $\alpha_{\mathrm{v}} \beta_{3}$ integrin is successful targeted and imaging of tumors [40]. Vascular-targeted imaging using functionalized polymerized vesicles (PVs) is biotinylated anti- $\alpha v \beta 3$ antibody (LM609) was conjugated to PVs that has specificity for endothelial cell receptors provide in vivo imaging studies in vascular associated antigens. PVs are designed to minimize reticuloendothelial system uptake and stay in the blood pool [41].

Biodegradable polydisulfide-based Gd complexes have been developed using a cleavable disulfide spacer for enhanced blood pool CAs. After MRI examination, PEG-g-poly(GdDTPA-co-l-cystine) breaks down macromolecules into smaller $\mathrm{Gd}$ complexes by exposure to endogenous thiols via disulfide-thiol exchange reaction to facilitate the Gd clearance [42]. In vivo MR imaging demonstrated strong contrast enhancement and large accumulation of CAs in the blood pool in mouse blood vessels, increased vascular retention, and prolonged blood pool contrast enhancement.

Protein binding blood-pool CAs include such as gadofosveset trisodium (MS-325) and gadocoletic acid trisodium (B22956) [43]. MS-325 currently in phase III clinical trials belongs to a chelated gadolinium contrast media. Breast tumor using a blood pool CA (MS-325) was compared to albumin-(Gd-DTPA)30 in rat breast 


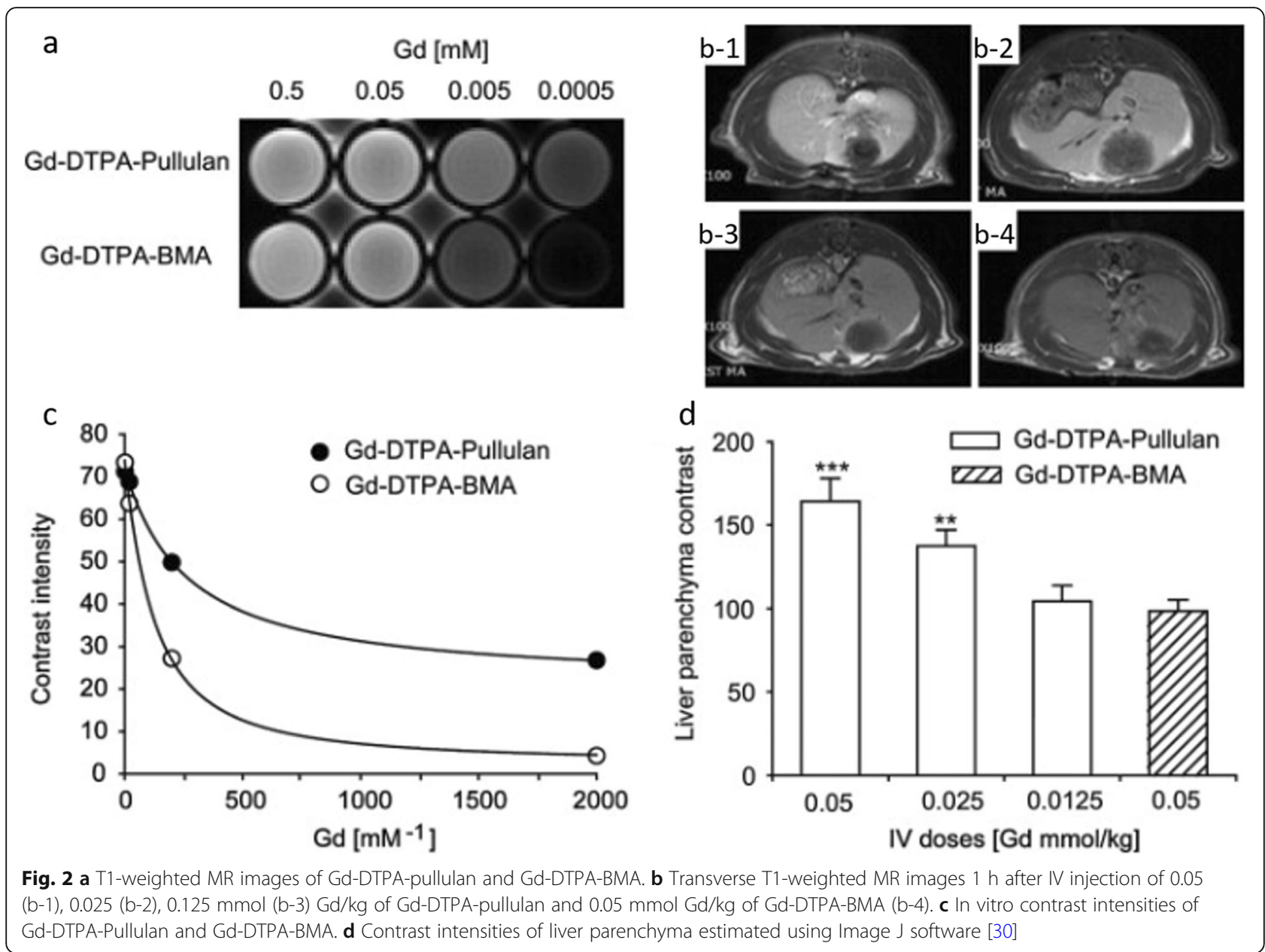

tumor [44]. The intravascular binding of MS-325 to serum albumin prolonged plasma half-life, increases the $\mathrm{T} 1$ relaxivity, and used as a MR angiography agent.

MR monitoring of Bevacizumab anti-angiogenesis therapy has been conducted using B22956/1 in human breast cancer model as a protein-binding CA for MRI assessments of tumor microvessels and it demonstrated that contrast effect was enhanced with B22956/1 [45]. The effect of B22956/1 in anti-angiogenesis treatment was tested in rat model using an anti-vascular endothelial growth factor antibody. Data indicated that B22956/ 1 shows a more sensitive detection of disease progression and responses to anti-angiogenesis therapy.

\section{Lymph node imaging}

Detection of tumor metastases in lymph nodes is critical for deciding tumor staging and planning therapies, however, small metastases in normal-sized lymph nodes are limited since current imaging techniques rely on the size and shape of the lymph node. Contrast-enhanced MR lymphography is an analysis method that provides a high contrast and resolution for the lymphatic system after administration with interstitial or intravenous applications [46].

Interstitial lymphographic CAs are highly accumulated in regional lymph nodes via fenestrated lymphatic capillaries and transport the lymph fluid to the lymph nodes. Interstitial lymphographic CAs include such as gadolinium chelates, superparamagnetic iron oxide particles (SIPO), ultrasmall superparamagnetic iron oxide particles (USPIO), liposome, micelle, and polymers. As an example of lymphographic CAs, subcutaneous injection of gadopentetate dimeglumine (Gd-DTPA) in dogs and human visualized the lymphatic pathways from the injection sites and showed enhanced accumulation in lymphatic vessels [47]. Gd-DTPA provided a selective assessment of lymph drainage from the tumor and showed the potential application against the early stage breast tumors.

\section{Atherosclerotic plaques}

MRI is a promising method for atherosclerotic plaque imaging. Atherosclerosis is a major contributor to coronary cerebrovascular disease, myocardial infarction, 
and artery disease [48, 49]. There is a need for targeted and effective CAs to allow noninvasive imaging of the cholesterol-rich atherosclerotic plaques in arteries [50]. High-density lipoprotein (HDL) based CA is one of the agents that targets atherosclerotic plaques. It is a bilayer nanodisk which is composed of phospholipids and known to interacts with atherosclerotic plaques $[50,51]$. Frias et al. reported that high-density lipoprotein (HDL)-like nanoparticle CA selectively targets atherosclerotic plaques [52]. In vivo MRI showed that most of the CA localized at the atherosclerotic plaque and MRI contrast intensity was maximum in plaques at $24 \mathrm{~h}$ post-injection. In addition, (HDL)-mimicking MRI CA using apoA-I-mimicking peptide $37 \mathrm{pA}$, apoA-I mimics has been reported to show effectiveness in plaque treatment in atherosclerosis mouse model and considered as a heart disease drug [53].

Reconstituted high-density lipoprotein (rHDL) nanoparticle platform enriched with Gd-based amphiphiles are applied as a plaque-specific MR imaging CA which allows better detection of vulnerable plaques. Chen et al. reported that Gd-loaded rHDL nanoparticles are highly accumulated in atherosclerotic plaques and enhanced the vessel wall with strong MR signal intensity. In details, they developed two palmitoyl chains have been conjugated to $\mathrm{A} 2$, the apolipoprotein $\mathrm{E}$ (apoE) derived peptide, to create P2A2. P2fA2 is the lipopeptide that P2A2 is modified with carboxyfluorescein. Using the P2fA2 enriched rHDL (rHDL-P2A2) nanoparticles, they showed enhanced detection of intraplaque macrophages that are associated with plaque vulnerability [54].

\section{Tumor}

Targeting and imaging of tumor vasculature plays a critical role to predict tumor response to therapy and to monitor of tumor angiogenesis. Thus, angiogenesis, growth, and metastasis of tumors, needs to develop accurate and non-invasive imaging CAs.

Rijpkema et al. illustrated that dynamic contrast-enhanced (DCE) MRI data is able to characterize tumors in humans [55]. CA using gadolinium (Gd) is used for the assessment of human tumors via IV bolus injection of Gd and monitored in time by T1-weighted MRI. The data provided tumor treatment response and rate of $\mathrm{CA}$ uptake in the tumor to evaluate treatment response and outcome. T1-weighted DCE MRI image showed that tumor was clearly distinguished from the surrounding tissues and suggested a potential of detecting metastasis.

Tumor targeting and imaging using quantum dots (QDs) [56] are also one of MR imaging CAs. For specific targeting, QDs are conjugated to an antibody for a prostate-specific membrane antigen (PSMA) for active tumor targeting. Bander et al. demonstrated that radiolabeled monoclonal antibody as a targeted prostate cancer metastasis showed enhanced accumulation and prolonged PSMA antibody at the tumor sites [57]. In addition, QDs conjugated to arginine-lysine-aspartic acid (RGD) peptides to target tumor vasculature displayed a specific affinity to angiogenic factor which is expressed in growing tumors [58].

Superparamagnetic iron oxide nanoparticles (SPION) applications in MRI provided higher contrast enhancement in MRI than conventional Gd-based CAs [59, 60]. Poly(TMSMA-r-PEGMA)@SPION which has a surface anchoring moiety and a protein-resistant moiety that is able to detect tumors in vivo using clinical MRI. SPION in the tumor area shows accumulation of iron oxide in the tumor tissue, successfully target the tumor tissue possibly via the EPR effect. When SPION administered intravenously to xenograft mice, T2-weighted MR images showed the specific accumulation within the tumor sites. After $4 \mathrm{~h}$ post injection, T2 signal dropped due to fast clearance, which indicates that cancer imaging can be obtained up to $4 \mathrm{~h} \mathrm{[60] \text {. }}$

To overcome limitations of nonspecific CAs, targeted CAs for MRI is designed by direct conjugation of an antibody or targeting moiety to a contrast agent. For example, avidin-biotin system was coupled to a dendrimer-based macromolecular MRI CA [61]. and conjugation of avidin and biotin provides targeting of Gd ions per antibody binding [62]. These reports demonstrate that targeting molecules may increase the delivery of the CA into specific regions for effective cancer diagnosis.

Artemov et al. developed a gadolinium-based MR CA to image the HER-2/neu Receptor [63]. The HER-2/neu receptor is a member of the epidermal growth factor which is overexpressed in breast cancers [64]. It has been reported that specific binding of avidin-Gd complexes to tumor cells using biotinylated anti-HER-2/neu monoclonal antibody (mAb) demonstrated Gd-labeled avidin was bind to the biotinylated $\mathrm{mAb}$ with high affinity [63]. Kim et al. also designed cancer recognizable MRI CAs (CR-CAs) using $\mathrm{pH}$ sensitive polymeric micelles [65]. The CR-Cas forms stable micelles at neutral $\mathrm{pH}$ with decreased $\mathrm{T} 1$ relaxivity (Fig. 3). Under tumor $\mathrm{pH}$, the micelles break apart and switch to water soluble polymers with increased $\mathrm{T} 1$ relaxivity. Thus, the exposed Gd accumulated in the tumor tissue and showed strong enhanced T1 contrast over time.

\section{Combination of MR contrast agent and drug}

Chemotherapy has long been applied in the treatment of various types of disease. However, combination of MR contrast agent and drug may overcome many limitations of conventional chemotherapy such as low targeting efficacy and side effects. To overcome the low contrast effect and low specific treatment efficacy various magnetic 

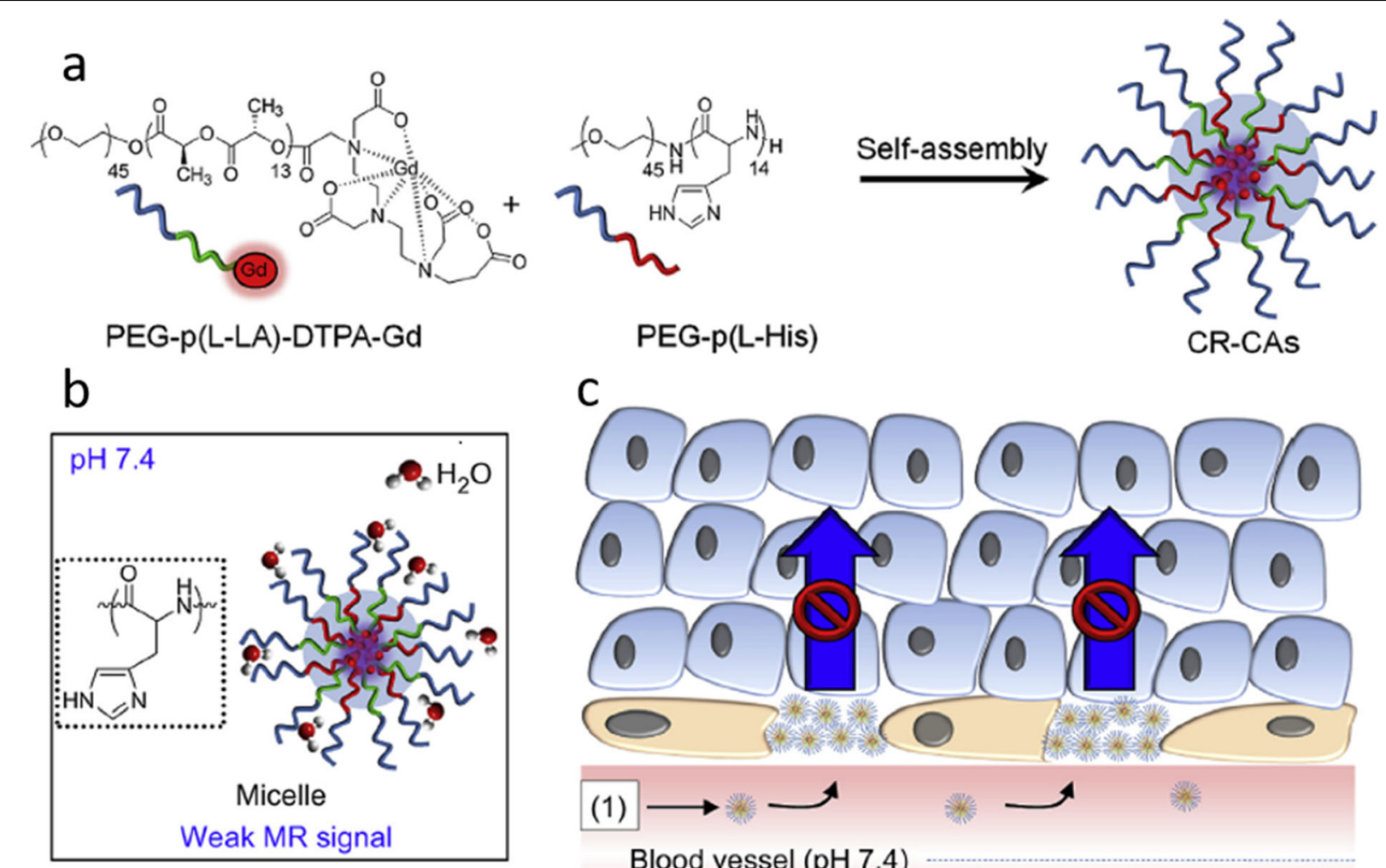

C
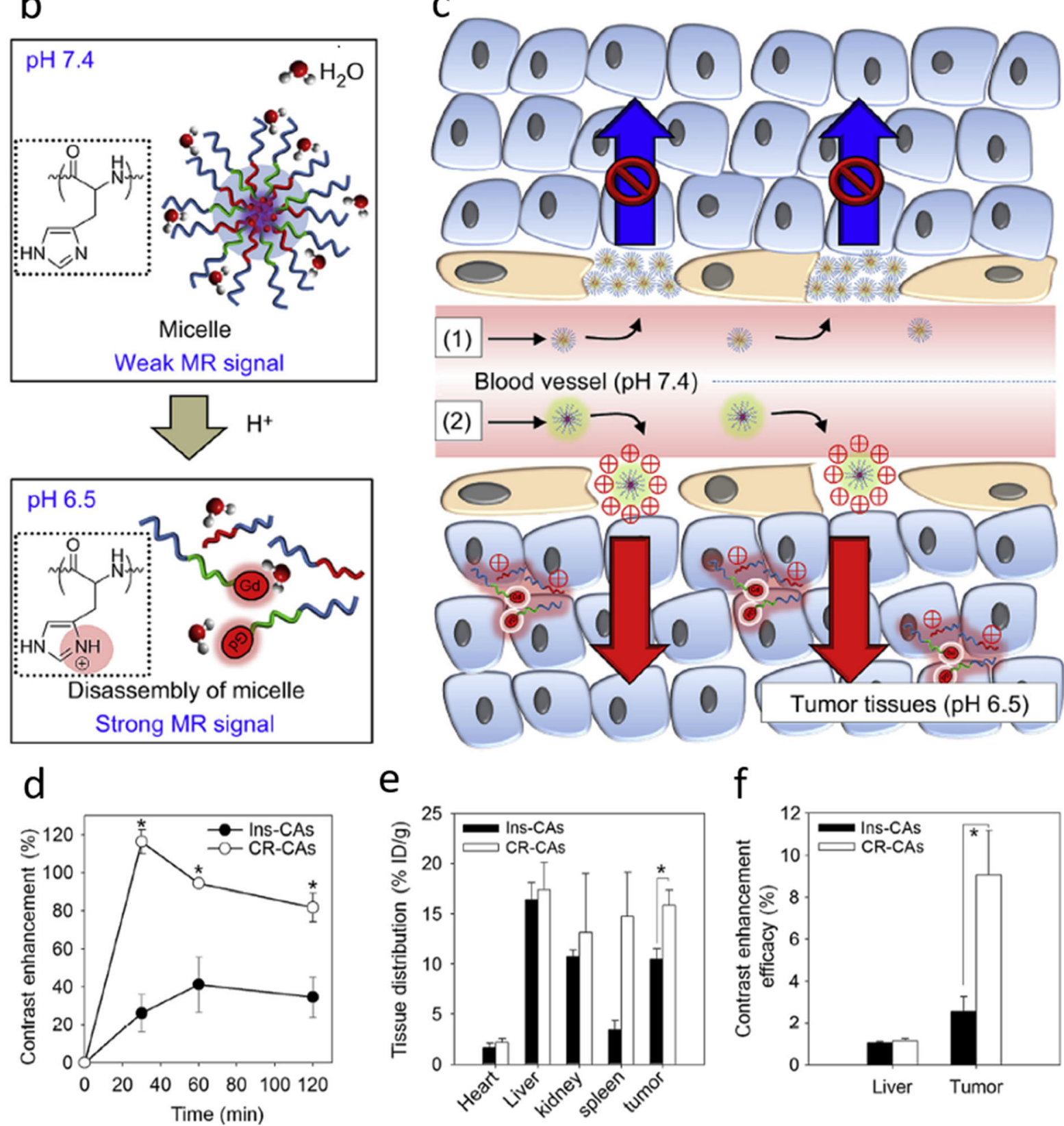

e
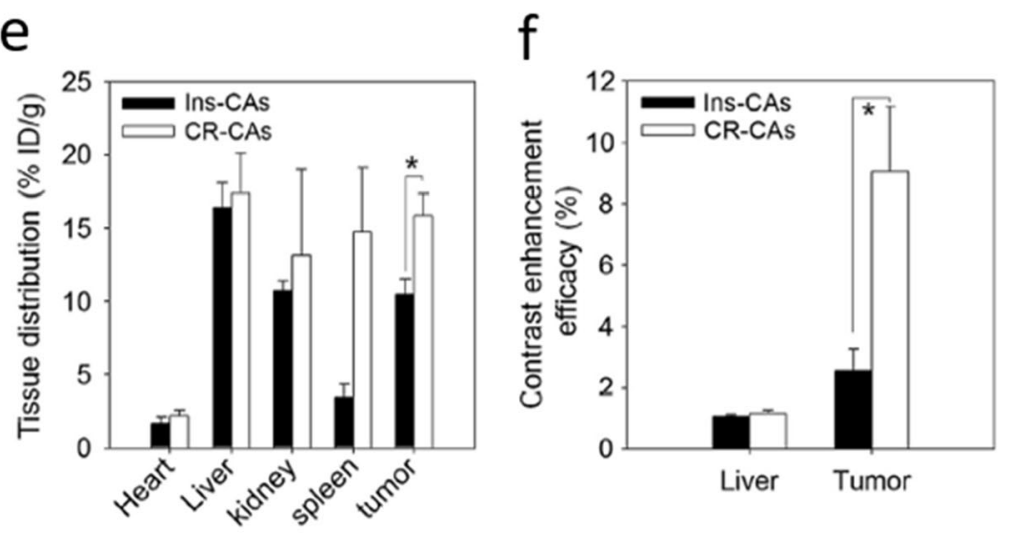

Fig. 3 (See legend on next page.) 
(See figure on previous page.)

Fig. 3 a Preparation of the cancer-recognizable MRI contrast agents (CR-CAs). b Schematic illustration of pH-dependent structural transformation and related MR signal changes in CR-CAs. c Schematic illustration of the tumor-accumulation behavior of conventional micelle (1) and CR-CAs (2). d Contrast enhancement vs. time after CR-CAs and Ins-CAs injection. e In vivo biodistribution of CR-CAs and Ins-CAs in CT26 bearing BALB/C mice. $\mathbf{f}$ Contrast enhancement efficacy of CR-CAs and Ins-Cas [65]

nanoparticles (MNP) have been developed for enhanced diagnostic. MNP is one of the nanoparticles with superparamagnetic property and used for MR contrast agent. MNPs appear to be very suitable for drug delivery and diagnosis. As well, they can be synthetized with particles of various sizes and properties in order to carry various molecules and to release in a specific environment. Recently, research has focused on the development of nanoparticle that incorporate multiple functions for multimodal imaging to enable for diagnostic at the same time. Xin Zhou et al. have recently described the properties of magnetic liposome with hydrophilic and hydrophobic drugs. Surface of magnetic liposome was coated with targeted peptide that is recognized by $\alpha_{v} \beta_{3}$ integrin receptor, which is overexpressed in tumor cells. Indeed, MNPs need to be coated with polymers and peptides to stabilize them and enhance their biocompatibility. Various polymers such as poly ethylene glycol(PEG) [66], dextran [67], chitosan [68], and polyethyleneimine (PEI) [69] are used to stabilize the MNPs to make mono-dispersed particles in the solution. Also, albumin is used to avoid immunogenicity, achieve tumor accumulation, and cellular uptake of drugs for enhanced therapeutic effect and diagnosis [70]. Many chemotherapeutic drugs [71-76] and siRNA treatments [77] have already been loaded in different nanoparticles and have demonstrated a great efficacy against different types of cancers. Combination of MR CA and drug has great potential due to the numerous advantages of MNPs. For example, Maeng et al. have shown higher MR sensitivity and anticancer efficacy that MNPs loaded with doxorubicin (a potent anti-cancer agent) against liver cancer in rat and rabbit cancer models (Fig. 4) [78].

\section{Combination of MR contrast agent and thermal therapy}

For the treatment of cancer, thermal therapies have numerous advantages. The technique is focal and repeatable with a minimally invasive application. There are 2 main types of thermal therapy: cool- or heat-based techniques [79]. Cryosurgery is based on the application of extreme cold to destroy tumors such as liver [80], lung cancers [81]. In recent years, the use of nanoparticles has

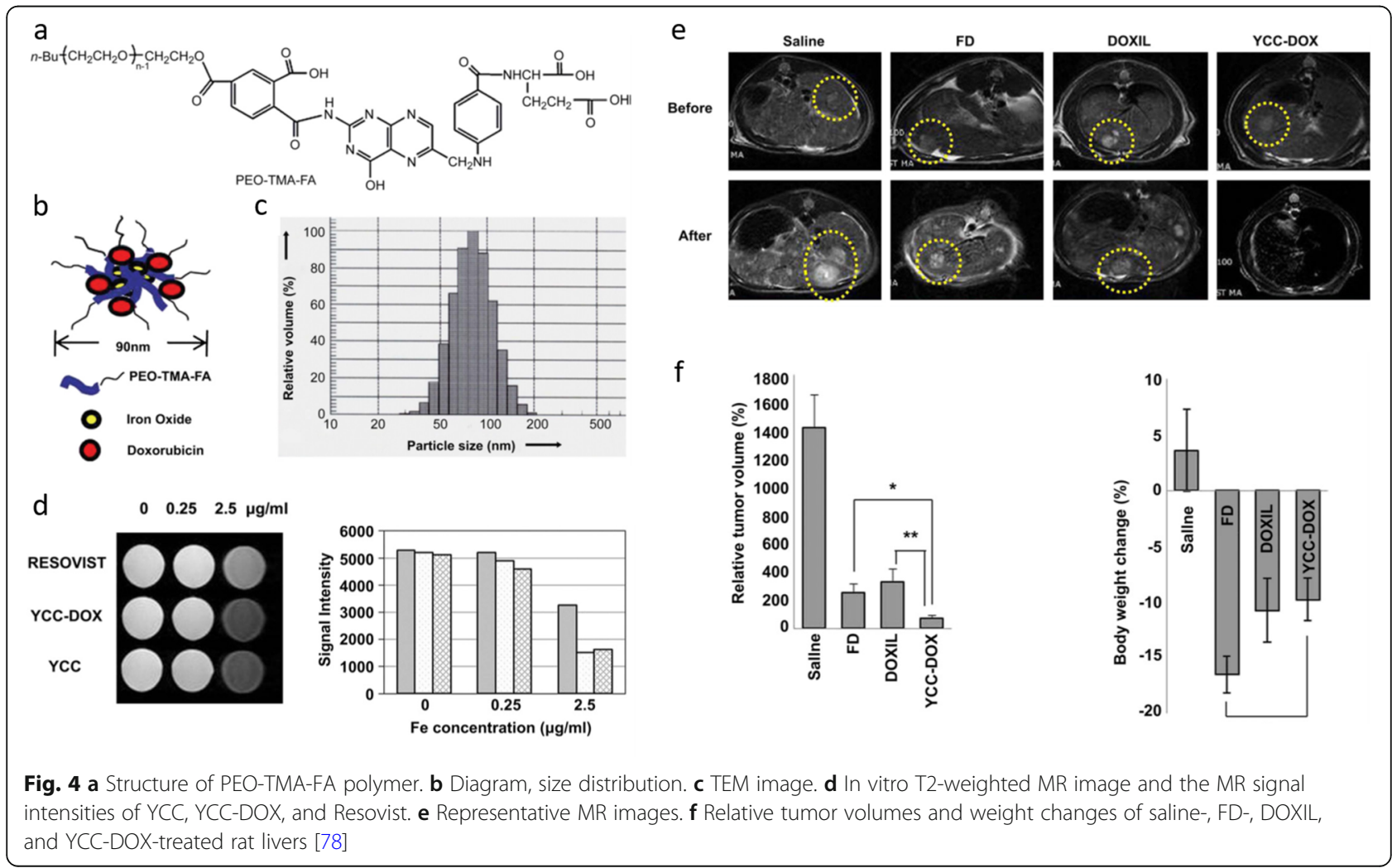


led to a new technique called nanocryosurgery [82]. which was proposed to improve freezing efficiency of the conventional cryosurgery. While the use of MNPs in cryosurgery is still in its infancy, in hyperthermal treatments MNPs have been investigated for decades. For hyperthermal treatment, different techniques are available, such as lasers [83, 84], high intensity focused ultrasound [85-87], radiofrequency currents or alternating magnetic field [88, 89].

Nanoparticles have been also investigated to deliver thermal energy to tumors. The different techniques use the properties of NPs inherent to their size and composition such as optical and magnetic characteristics, thermal or electrical conductivity. For example, photothermal therapy uses laser light to heat NPs to selectively kill cells which incorporated these NPs. More recently, Gd tethered gold MNP have been shown to improve the stability and bioavailability of organic photosensitizer molecules [90]. Owing to its intrinsic high optical absorption in the near-infrared region, functionalized gold nanorod can combine both photothermal hyperthermia and imaging for optimum therapeutic efficiency [91].

The use of an external magnetic field is another technique to treat cancer with magnetic NPs. Indeed, minimally invasive magnetic heating therapy uses SPIO MNPs to generate heat (with an external alternating magnetic field) to specific tumor areas. So far, different cancer types such as brain [92], breast [93], prostate [94] and liver cancers [95-97] have been treated using this technique. The advantage of this technique is that MNPs can be injected directly into the tumor before thermotherapy and MNPs seem to remain almost completely in the tumor allowing for repeated treatments. Indeed, ultrasound mediated hyperthermal system also has been investigated for enhanced therapeutic efficacy.

\section{Combination of MR contrast agent and photodynamic therapy}

Combination of MR contrast agent and photodynamic therapy (PDT) provides synergetic effect for treatment

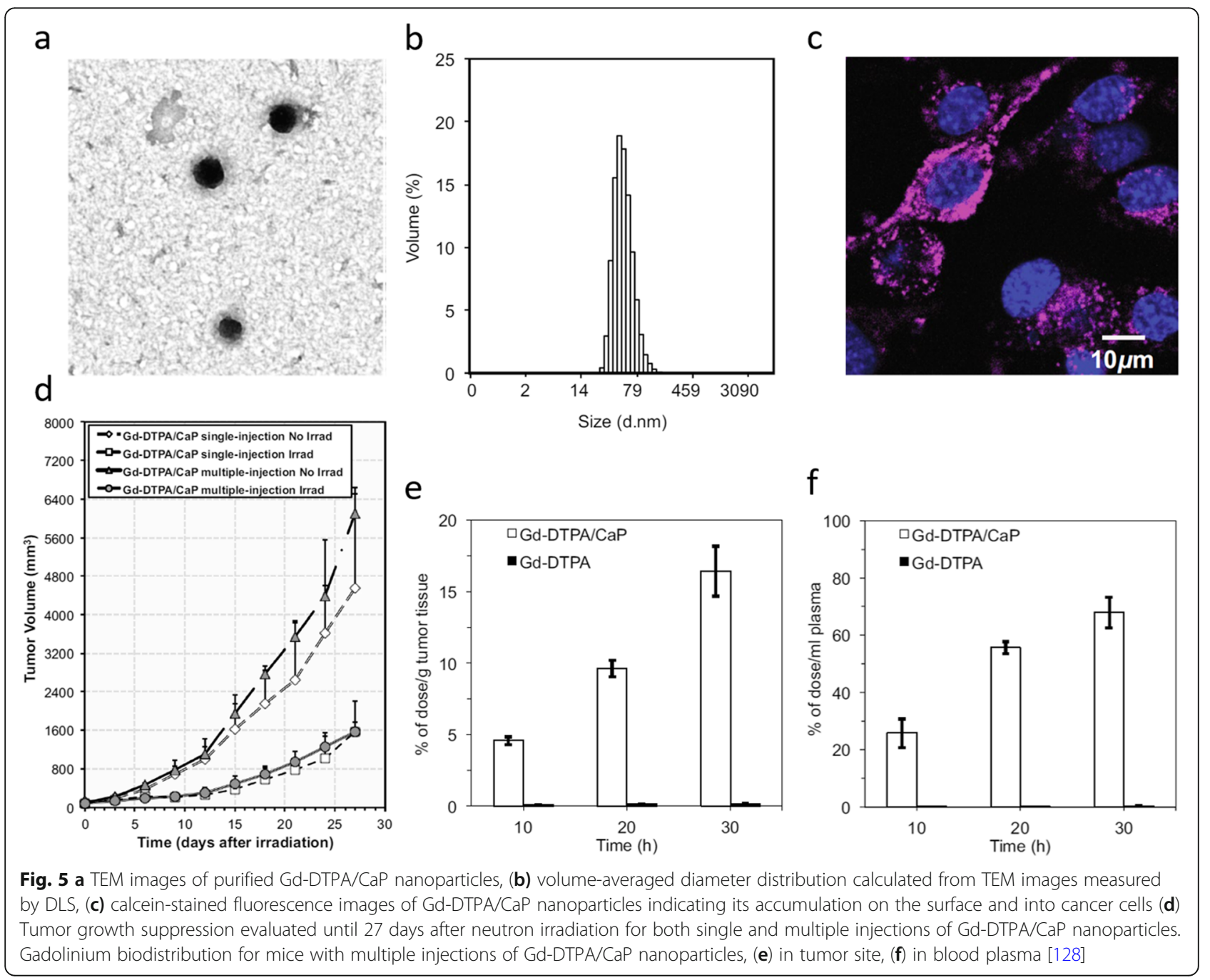


of cancer. PDT is a therapy consisting of visible light and photosensitizers. Photosensitizers are activated by absorption of light to generate the reactive oxygen species (ROS). ROS produced by PDT damage leads to tumor cell death and induction of antitumor immune response. In a recent research article, Jing Lin et al. have reported the current progress in the multifunctional theranostic platform based on photosensitizer-loaded gold nanoparticle(GNP). GNP encapsulate active compound for MR imaging, PDT, and photo thermal therapy using single wavelength laser irradiation [98]. Han et al. have reported the theranostic micelles based on upconversion nanoparticles for dual modality imaging and photodynamic therapy in hepatocellular carcinoma. This micelle showed noticeable antitumor efficacy compared to chemotherapy alone [99]. Skupin-Mrugalska et al. have developed the theranostic liposomes bearing gadolinium and zinc phthalocyanine as a bimodal carrier for MRI and PDT. This liposome showed enhanced contrast properties in the presence of pegylated phospholipid by increased the water proton nearby gadolinium. Indeed, cell viability of hela cell was significantly inhibited under laser exposure [100].

\section{Neutron capture therapy}

Neutron capture therapy is one of the treatment methods for treating early cancer, mainly using ${ }^{10} \mathrm{~B}$ containing molecules. ${ }^{10} \mathrm{~B}$ is non-reactive atom that absorb low-energy and break into ${ }^{4} \mathrm{He}^{2+}$ and ${ }^{7} \mathrm{Li}^{3+}$ ions, then releasing their energy at short range causing cytotoxic effect to cancer cells [101]. Unlike ${ }^{10} \mathrm{~B}$, there has been interest in use of ${ }^{155} \mathrm{Gd}$ and ${ }^{157} \mathrm{Gd}$ as neutron capture therapy agent for several reasons. First, reaction with $\mathrm{Gd}$ and neutron capture induces complex inner-shell transitions that leads emission of Auger electron, $\gamma$-rays, and photon. Auger electron and $\gamma$-rays show cytotoxicity at short distances and long distances, respectively [102]. Second, Gd compounds have been used as a T1 CA for MR imaging. Because of these reasons, Gd is considered to be a suitable material for theranostic. Conventional MR CAs have been tested for neutron capture therapy. However, they showed low uptakes in tumor after intravenous injection [103]. To increase the accumulation of gadolinium in the tumor, various Gd containing polymers have been investigated. Core shell nanoparticle made of $\mathrm{Gd}$ and calcium phosphate(Gd-DTPA/CaP) have been synthesized. Novriana et al. have performed antitumor evaluation for single and multiple injection of Gd-DTPA/CaP nanoparticles. They could observe tumor suppression after neutron irradiation. However, there was no significant difference in antitumor efficacy between single and multiple injection (Fig. 5) [104]. In addition, various $\mathrm{Gd}$ containing polymers have been investigated, including Gd-loaded chitosan nanoparticles
[105-107], and Gd-boron complex [108]. More recently, Dewi et al. proposed Gd-neutron capture therapy using Gd-entrapped liposome as Gd delivery agent. The concentration of $\mathrm{Gd}$ in tumor site was determined using ICP-MS at 2, 12, $24 \mathrm{~h}$ after injection. The accumulation of Gd seemed to be much higher than CA only; without entrapping it into liposome. After neutron irradiation, liposome treated group showed 4 times higher tumor suppression [107].

\section{Conclusion}

Recently, theranostic MR CAs have been developed and various studies are conducted to enhance the contrast effect. Studies have been carried out to maximize the contrast effect by reducing the $\mathrm{T} 1$ relaxation time and $\mathrm{R} 2$ relaxivity, or to increase the water exchange rate to enhance the contrast effect. After that, the CA does not only increase the contrast effect, but also obtain a bright contrast effect in a specific condition or a specific organ, and the CA appears when the contrast is decomposed by an enzyme. A lot of researches have been investigated to synthesis materials that show treatment even with single administration. The advantages of theranostic are more convenient and efficient to treat simultaneously with enhanced contrast effect. Various methods have been tried to obtain these effects. First, the CA and the drug are sealed at the same time to be expressed at specific disease sites and simultaneously performed the contrast and treatment. As another method, there is a method of simultaneous thermotherapy with $\mathrm{CA}$ to generate heat and kill cancer cells. Another method is neutron capture therapy, which is a method of simultaneous treatment. Recently, variety of methods have been tried and customized theranostic materials will be developed for personalized treatment.

\section{Acknowledgements \\ This work was supported by the Basic Research Laboratory (BRL) program (NRF-2015R1A4A1042350), through the National Research Foundation of Korea (NRF) grant funded by the Korean government (Ministry of Science, ICT and future Planning). \\ Funding \\ Basic Research Laboratory (BRL) program of the National Research Foundation of Korea was funded by the Ministry of Science (NRF-2015R1A4A1042350).}

\section{Authors' contributions}

All authors wrote and revised the manuscript. All authors read and approved the final manuscript.

\section{Ethics approval and consent to participate} Not applicable.

Consent for publication

Not applicable.

Competing interests

The authors declare that they have no competing interests. 


\section{Publisher's Note}

Springer Nature remains neutral with regard to jurisdictional claims in published maps and institutional affiliations.

Received: 8 May 2018 Accepted: 18 July 2018

Published online: 27 July 2018

\section{References}

1. Pysz MA, Gambhir SS, Willmann JK. Molecular imaging: current status and emerging strategies. Clin Radiol. 2010;65:500-16.

2. Sumer B, Gao J, Theranostic nanomedicine for cancer. 2008

3. Ugander M, Bagi PS, Oki AJ, Chen B, Hsu L-Y, Aletras AH, Shah S, Greiser A, Kellman P, Arai AE. Myocardial edema as detected by pre-contrast T1 and T2 CMR delineates area at risk associated with acute myocardial infarction. J Am Coll Cardiol Img. 2012:5:596-603.

4. Chalela JA, Kidwell CS, Nentwich LM, Luby M, Butman JA, Demchuk AM, Hill MD, Patronas N, Latour L, Warach S. Magnetic resonance imaging and computed tomography in emergency assessment of patients with suspected acute stroke: a prospective comparison. Lancet. 2007;369:293-8.

5. Yao L, Lee J. Occult intraosseous fracture: detection with MR imaging. Radiology. 1988;167:749-51.

6. Chen XS. Introducing theranostics journal-from the editor-in-chief. Theranostics. 2011;1:1.

7. Conde J, Bao C, Cui D, Baptista PV, Tian F. Antibody-drug gold nanoantennas with Raman spectroscopic fingerprints for in vivo tumour theranostics. J Control Release. 2014;183:87-93.

8. Gautam A, Kapoor P, Chaudhary K, Kumar R, Raghava G, Consortium SDD. Tumor homing peptides as molecular probes for cancer therapeutics, diagnostics and theranostics. Curr Med Chem. 2014;21:2367-91.

9. Shigdar S, Macdonald J, O'Connor M, Wang T, Xiang D, Al Shamaileh H, Qiao L, Wei M, Zhou S-F, Zhu Y. Aptamers as theranostic agents: modifications, serum stability and functionalisation. Sensors. 2013;13:13624-37.

10. Xiang D, Shigdar S, Qiao G, Wang T, Kouzani AZ, Zhou S-F, Kong L, Li Y, Pu C, Duan W. Nucleic acid aptamer-guided cancer therapeutics and diagnostics: the next generation of cancer medicine. Theranostics. 2015:5:23.

11. Shrestha R, Elsabahy M, Luehmann H, Samarajeewa S, Florez-Malaver S, Lee NS, Welch MJ, Liu Y, Wooley KL. Hierarchically assembled theranostic nanostructures for siRNA delivery and imaging applications. J Am Chem Soc. 2012;134:17362-5.

12. Liu Y, Feng L, Liu T, Zhang L, Yao Y, Yu D, Wang L, Zhang N. Multifunctional $\mathrm{pH}$-sensitive polymeric nanoparticles for theranostics evaluated experimentally in cancer. Nanoscale. 2014;6:3231-42.

13. Moon GD, Choi S-W, Cai X, Li W, Cho EC, Jeong U, Wang LV, Xia Y. A new theranostic system based on gold nanocages and phase-change materials with unique features for photoacoustic imaging and controlled release. J Am Chem Soc. 2011;133:4762-5.

14. Liu P, Yue C, Shi B, Gao G, Li M, Wang B, Ma Y, Cai L. Dextran based sensitive theranostic nanoparticles for near-infrared imaging and photothermal therapy in vitro. Chem Commun. 2013;49:6143-5.

15. Zhang Z, Wang J, Chen C. Gold nanorods based platforms for lightmediated theranostics. Theranostics. 2013;3:223.

16. Kiessling F, Fokong S, Koczera P, Lederle W, Lammers T. Ultrasound microbubbles for molecular diagnosis, therapy, and theranostics. J Nucl Med. 2012:53:345-8.

17. Ogawa S, Lee T-M, Kay AR, Tank DW. Brain magnetic resonance imaging with contrast dependent on blood oxygenation. Proc Natl Acad Sci. 1990:87:9868-72

18. Selskog P, Heiberg E, Ebbers T, Wigstrom L, Karlsson M. Kinematics of the heart: strain-rate imaging from time-resolved three-dimensional phase contrast MRI. IEEE Trans Med Imaging. 2002;21:1105-9.

19. Kupersmith MJ, Alban T, Zeiffer B, Lefton D. Contrast-enhanced MRI in acute optic neuritis: relationship to visual performance. Brain. 2002;125:812-22.

20. Moser T, Dosch J-C, Moussaoui A, Dietemann J-L. Wrist ligament tears: evaluation of MRI and combined MDCT and MR arthrography. Am J Roentgenol. 2007;188:1278-86.

21. Bashir A, Gray M, Hartke J, Burstein D. Nondestructive imaging of human cartilage glycosaminoglycan concentration by MRI. Magn Reson Med. 1999;41:857-65.

22. Zhao Q, Wang L, Cheng R, Mao L, Arnold RD, Howerth EW, Chen ZG, Platt S. Magnetic nanoparticle-based hyperthermia for head \& neck cancer in mouse models. Theranostics. 2012;2:113.
23. Brown RW, Haacke EM, Cheng Y-CN, Thompson MR, Venkatesan R. Resonance imaging: physical principles and sequence design: second edition. Wiley Blackwell; 2014. https://doi.org/10.1002/9781118633953.

24. Carreira GC, Gemeinhardt O, Beyersdorff D, Schnorr J, Taupitz M, Lüdemann L. Effects of water exchange on MRI-based determination of relative blood volume using an inversion-prepared gradient echo sequence and a blood pool contrast medium. Magn Reson Imaging. 2009;27:360-9.

25. Na HB, Song IC, Hyeon T. Inorganic nanoparticles for MRI contrast agents. Adv Mater. 2009:21:2133-48.

26. Bloembergen N, Morgan L. Proton relaxation times in paramagnetic solutions. Effects of electron spin relaxation. J Chem Phys. 1961;34:842-50.

27. Bloembergen N. Proton relaxation times in paramagnetic solutions. J Chem Phys. 1957:27:572-3.

28. Solomon I, Bloembergen N. Nuclear magnetic interactions in the HF molecule. J Chem Phys. 1956:25:261-6.

29. Ba-Ssalamah A, Uffmann M, Saini S, Bastati N, Herold C, Schima W. Clinical value of MRI liver-specific contrast agents: a tailored examination for a confident noninvasive diagnosis of focal liver lesions. Eur Radiol. 2009;19:342-57.

30. Yim H, Yang S-G, Jeon YS, Park IS, Kim M, Lee DH, Bae YH, Na K. The performance of gadolinium diethylene triamine pentaacetate-pullulan hepatocyte-specific T1 contrast agent for MRI. Biomaterials. 2011:32:5187-94.

31. Toft KG, Hustvedt S, Grant D, Martinsen I, Gordon P, Friisk G, Korsmo A, Skotland T. Metabolism and pharmacokinetics of MnDPDP in man. Acta Radiol. 1997;38:677-89.

32. Elizondo G, Fretz C, Stark D, Rocklage S, Quay S, Worah D, Tsang Y, Chen M, Ferrucci J. Preclinical evaluation of MnDPDP: new paramagnetic hepatobiliary contrast agent for MR imaging. Radiology. 1991;178:73-8.

33. Rummeny E, Ehrenheim C, Gehl H, Hamm B, Laniado M, Lodemann K, Schmiedel E, Steudel A, Vogl TG. Manganese-DPDP as a hepatobiliary contrast agent in the magnetic resonance imaging of liver tumors: results of clinical phase II trials in Germany including 141 patients. Investig Radiol. 1991:26:S142-S5.

34. de Haën C, Lorusso V , Tirone P. Hepatic transport of gadobenate dimeglumine in TR- rats. Acad Radiol. 1996:3:S452-S4.

35. Schuhmann-Giampieri G. Liver contrast media for magnetic resonance imaging. Interrelations between pharmacokinetics and imaging. Investig Radiol. 1993;28:753-61.

36. Spinazzi A, Lorusso V, Pirovano G, Taroni P, Kirchin M, Davies A. Multihance clinical pharmacology: biodistribution and MR enhancement of the liver Acad Radiol. 1998:5:S86-S9.

37. Weinmann HJ, Schuhmann-Giampieri G, Schmitt-Willich H, Vogler H, Frenzel T, Gries H. A new lipophilic gadolinium chelate as a tissue-specific contrast medium for MRI. Magn Reson Med. 1991;22:233-7.

38. Reimer P, Schneider G, Schima W. Hepatobiliary contrast agents for contrast-enhanced MRI of the liver: properties, clinical development and applications. Eur Radiol. 2004;14:559-78.

39. Mohs AM, Lu Z-R. Gadolinium (III)-based blood-pool contrast agents for magnetic resonance imaging: status and clinical potential. Expert Opinion on Drug Delivery. 2007:4:149-64.

40. Winter PM, Morawski AM, Caruthers SD, Fuhrhop RW, Zhang H, Williams TA, Allen JS, Lacy EK, Robertson JD, Lanza GM. Molecular imaging of angiogenesis in early-stage atherosclerosis with av $\beta 3$-integrin-targeted nanoparticles. Circulation. 2003:108:2270-4.

41. Li KC, Bednarski MD. Vascular-targeted molecular imaging using functionalized polymerized vesicles. J Magn Reson Imaging. 2002;16:388-93.

42. Mohs AM, Wang X, Goodrich KC, Zong Y, Parker DL, Lu Z-R. PEG-g-poly (GdDTPA-co-L-cystine): a biodegradable macromolecular blood pool contrast agent for MR imaging. Bioconjug Chem. 2004;15:1424-30.

43. de Haën C, Anelli PL, Lorusso V, Morisetti A, Maggioni F, Zheng J, Uggeri F, Cavagna FM. Gadocoletic acid trisodium salt (b22956/1): a new blood pool magnetic resonance contrast agent with application in coronary angiography. Investig Radiol. 2006;41:279-91.

44. Turetschek K, Floyd E, Helbich T, Roberts TP, Shames DM, Wendland MF, Carter WO, Brasch RC. MRI assessment of microvascular characteristics in experimental breast tumors using a new blood pool contrast agent (MS-325) with correlations to histopathology. J Magn Reson Imaging. 2001;14:237-42.

45. Preda A, Novikov V, Möglich M, Turetschek K, Shames DM, Brasch RC, Cavagna FM, Roberts TP. MRI monitoring of Avastin ${ }^{\mathrm{TM}}$ antiangiogenesis therapy using B22956/1, a new blood pool contrast agent, in an experimental model of human cancer. J Magn Reson Imaging. 2004;20:865-73. 
46. Misselwitz B. MR contrast agents in lymph node imaging. Eur J Radiol. 2006; 58:375-82.

47. Suga K, Yuan Y, Ogasawara N, Okada M, Matsunaga N. Localization of breast sentinel lymph nodes by MR lymphography with a conventional gadolinium contrast agent. Acta Radiol. 2003;44:35-42.

48. Stary HC. Natural history and histological classification of atherosclerotic lesions: an update. Arterioscler Thromb Vasc Biol. 2000;20:1177-8.

49. Fuster V, Moreno PR, Fayad ZA, Corti R, Badimon JJ. Atherothrombosis and high-risk plaque: part I: evolving concepts. J Am Coll Cardiol. 2005;46:937-54

50. Cormode DP, Briley-Saebo KC, Mulder WJ, Aguinaldo JGS, Barazza A, Ma Y, Fisher EA, Fayad ZA. An ApoA-I mimetic peptide high-density-lipoproteinbased MRI contrast agent for atherosclerotic plaque composition detection. Small. 2008;4:1437-44.

51. Frias JC, Ma Y, Williams KJ, Fayad ZA, Fisher EA. Properties of a versatile nanoparticle platform contrast agent to image and characterize atherosclerotic plaques by magnetic resonance imaging. Nano Lett. 2006;6:2220-4.

52. Frias JC, Williams KJ, Fisher EA, Fayad ZA. Recombinant HDL-like nanoparticles: a specific contrast agent for MRI of atherosclerotic plaques. J Am Chem Soc. 2004;126:16316-7.

53. Datta G, Chaddha M, Hama S, Navab M, Fogelman AM, Garber DW, Mishra VK, Epand RM, Epand RF, Lund-Katz S. Effects of increasing hydrophobicity on the physical-chemical and biological properties of a class a amphipathic helical peptide. J Lipid Res. 2001;42:1096-104.

54. Chen W, Vucic E, Leupold E, Mulder WJ, Cormode DP, Briley-Saebo KC, Barazza A, Fisher EA, Dathe M, Fayad ZA. Incorporation of an apoE-derived lipopeptide in high-density lipoprotein MRI contrast agents for enhanced imaging of macrophages in atherosclerosis. Contrast Media Mol Imaging. 2008;3:233-42

55. Rijpkema M, Kaanders JH, Joosten F, van der Kogel AJ, Heerschap A. Method for quantitative mapping of dynamic MRI contrast agent uptake in human tumors. J Magn Reson Imaging. 2001;14:457-63.

56. Rhyner MN, Smith AM, Gao X, Mao H, Yang L, Nie S, Quantum dots and multifunctional nanoparticles: new contrast agents for tumor imaging. 2006.

57. Bander NH, Trabulsi EJ, Kostakoglu L, Yao D, Vallabhajosula S, Smith-Jones P, Joyce MA, Milowsky M, Nanus DM, Goldsmith SJ. Targeting metastatic prostate cancer with radiolabeled monoclonal antibody J591 to the extracellular domain of prostate specific membrane antigen. J Urol. 2003;170:1717-21.

58. Cai Q-Y, Kim SH, Choi KS, Kim SY, Byun SJ, Kim KW, Park SH, Juhng SK, Yoon K-H. Colloidal gold nanoparticles as a blood-pool contrast agent for X-ray computed tomography in mice. Investig Radiol. 2007;42:797-806.

59. Aime S, Cabella C, Colombatto S, Geninatti Crich S, Gianolio E, Maggioni F. Insights into the use of paramagnetic Gd (III) complexes in MR-molecular imaging investigations. J Magn Reson Imaging. 2002;16:394-406.

60. Baghi M, Mack MG, Hambek M, Rieger J, Vogl T, Gstoettner W, Knecht R. The efficacy of MRI with ultrasmall superparamagnetic iron oxide particles (USPIO) in head and neck cancers. Anticancer Res. 2005;25:3665-70.

61. Kobayashi H, Kawamoto S, Jo S-K, Bryant HL, Brechbiel MW, Star RA. Macromolecular MRI contrast agents with small dendrimers: pharmacokinetic differences between sizes and cores. Bioconjug Chem. 2003;14:388-94.

62. Morawski AM, Lanza GA, Wickline SA. Targeted contrast agents for magnetic resonance imaging and ultrasound. Curr Opin Biotechnol. 2005;16:89-92.

63. Artemov D, Mori N, Ravi R, Bhujwalla ZM. Magnetic resonance molecular imaging of the HER-2/neu receptor. Cancer Res. 2003;63:2723-7.

64. Kim YS, Konoplev SN, Montemurro F, Hoy E, Smith TL, Rondón G, Champlin RE, Sahin AA, Ueno NT. HER-2/neu overexpression as a poor prognostic factor for patients with metastatic breast cancer undergoing high-dose chemotherapy with autologous stem cell transplantation. Clin Cancer Res. 2001;7:4008-12.

65. Kim KS, Park W, Hu J, Bae YH, Na K. A cancer-recognizable MRI contrast agents using pH-responsive polymeric micelle. Biomaterials. 2014;35:337-43.

66. Anbarasu M, Anandan M, Chinnasamy E, Gopinath V, Balamurugan K. Synthesis and characterization of polyethylene glycol (PEG) coated Fe3O4 nanoparticles by chemical co-precipitation method for biomedical applications. Spectrochim Acta A Mol Biomol Spectrosc. 2015;135:536-9.

67. Saraswathy A, Nazeer SS, Nimi N, Arumugam S, Shenoy SJ, Jayasree RS. Synthesis and characterization of dextran stabilized superparamagnetic iron oxide nanoparticles for in vivo MR imaging of liver fibrosis. Carbohydr Polym. 2014;101:760-8.

68. Castelló J, Gallardo M, Busquets MA, Estelrich J. Chitosan (or alginate)coated iron oxide nanoparticles: a comparative study. Colloids Surf A Physicochem Eng Asp. 2015;468:151-8.

69. Yoon GJ, Lee SY, Lee SB, Park GY, Choi JH. Synthesis of Iron oxide/gold composite nanoparticles using Polyethyleneimine as a polymeric active stabilizer for development of a dual imaging probe. Nanomaterials. 2018;8(5):300.

70. Zhang M, Xing L, Ke H, He Y-J, Cui P-F, Zhu Y, Jiang G, Qiao J-B, Lu N, Chen H. $\mathrm{MnO}_{2}$-Based Nanoplatform Serves as Drug Vehicle and MRI Contrast Agent for Cancer Theranostics. ACS Appl Mater Interfaces. 2017;9:11337-44.

71. Sundaresan V, Menon JU, Rahimi M, Nguyen KT, Wadajkar AS. Dualresponsive polymer-coated iron oxide nanoparticles for drug delivery and imaging applications. Int J Pharm. 2014;466:1-7.

72. Liong M, Lu J, Kovochich M, Xia T, Ruehm SG, Nel AE, Tamanoi F, Zink JI. Multifunctional inorganic nanoparticles for imaging, targeting, and drug delivery. ACS Nano. 2008;2:889-96.

73. Nasongkla N, Bey E, Ren J, Ai H, Khemtong C, Guthi JS, Chin S-F, Sherry AD, Boothman DA, Gao J. Multifunctional polymeric micelles as cancer-targeted, MRI-ultrasensitive drug delivery systems. Nano Lett. 2006;6:2427-30.

74. Fan C-H, Ting C-Y, Lin H-J, Wang C-H, Liu H-L, Yen T-C, Yeh C-K. SPIOconjugated, doxorubicin-loaded microbubbles for concurrent MRI and focused-ultrasound enhanced brain-tumor drug delivery. Biomaterials. 2013;34:3706-15.

75. Menjoge AR, Kannan RM, Tomalia DA. Dendrimer-based drug and imaging conjugates: design considerations for nanomedical applications. Drug Discov Today. 2010;15:171-85.

76. Janib SM, Moses AS, MacKay JA. Imaging and drug delivery using theranostic nanoparticles. Adv Drug Deliv Rev. 2010;62:1052-63.

77. Lin G, Zhu W, Yang L, Wu J, Lin B, Xu Y, Cheng Z, Xia C, Gong Q, Song B. Delivery of siRNA by MRI-visible nanovehicles to overcome drug resistance in MCF-7/ADR human breast cancer cells. Biomaterials. 2014;35:9495-507

78. Maeng JH, Lee D-H, Jung KH, Bae Y-H, Park I-S, Jeong S, Jeon Y-S, Shim C-K, Kim W, Kim J. Multifunctional doxorubicin loaded superparamagnetic iron oxide nanoparticles for chemotherapy and magnetic resonance imaging in liver cancer. Biomaterials. 2010;31:4995-5006.

79. Klein PP: Apparatus for localized heat and cold therapy. Google Patents; 1990

80. Zhou XD, Tang ZY. Cryotherapy for primary liver cancer. In: Seminars in surgical oncology: Wiley Online Library. 1998;14(2):171-4.

81. Vergnon J, Huber R, Moghissi K. Place of cryotherapy, brachytherapy and photodynamic therapy in therapeutic bronchoscopy of lung cancers. Eur Respir J. 2006;28:200-18.

82. Yan J-F, Liu J. Nanocryosurgery and its mechanisms for enhancing freezing efficiency of tumor tissues. Nanomedicine. 2008;4:79-87.

83. Svaasand LO, Boerslid T, Oeveraasen M. Thermal and optical properties of living tissue: application to laser-induced hyperthermia. Lasers Surg Med. 1985;5:589-602.

84. Terentyuk GS, Maslyakova GN, Suleymanova LV, Khlebtsov NG, Khlebtsov BN, Akchurin GG, Maksimova IL, Tuchin W. Laser-induced tissue hyperthermia mediated by gold nanoparticles: toward cancer phototherapy. J Biomed Opt. 2009;14:021016.

85. Marmor JB, Hahn GM. Ultrasound heating in previously irradiated sitest. International Journal of Radiation Oncology Biology Physics. 1978;4:1029-32.

86. Marmor JB, Pounds D, Postic TB, Hahn GM. Treatment of superficial human neoplasms by local hyperthermia induced by ultrasound. Cancer. 1979;43:188-97.

87. Diederich CJ, Hynynen K. Ultrasound technology for hyperthermia. Ultrasound Med Biol. 1999;25:871-87.

88. Jordan A, Scholz R, Wust P, Fähling H, Felix R. Magnetic fluid hyperthermia (MFH): Cancer treatment with AC magnetic field induced excitation of biocompatible superparamagnetic nanoparticles. J Magn Magn Mater. 1999; 201:413-9.

89. Rosensweig RE. Heating magnetic fluid with alternating magnetic field. J Magn Magn Mater. 2002;252:370-4.

90. Hu D-H, Sheng Z-H, Zhang P-F, Yang D-Z, Liu S-H, Gong P, Gao D-Y, Fang S-T, Ma Y-F, Cai L-T. Hybrid gold-gadolinium nanoclusters for tumor-targeted NIRF/CT/MRI triple-modal imaging in vivo. Nanoscale. 2013;5:1624-8.

91. Huff TB, Tong L, Zhao Y, Hansen MN, Cheng J-X, Wei A, Hyperthermic effects of gold nanorods on tumor cells. 2007. 
92. Jordan A, Scholz R, Maier-Hauff K, van Landeghem FK, Waldoefner N, Teichgraeber U, Pinkernelle J, Bruhn H, Neumann F, Thiesen B. The effect of thermotherapy using magnetic nanoparticles on rat malignant glioma. J Neuro-Oncol. 2006;78:7-14

93. Hilger I, Hergt R, Kaiser WA. Towards breast cancer treatment by magnetic heating. J Magn Magn Mater. 2005:293:314-9.

94. Johannsen M, Gneveckow U, Thiesen B, Taymoorian $\mathrm{K}$, Cho CH, Waldöfner N, Scholz R, Jordan A, Loening SA, Wust P. Thermotherapy of prostate cancer using magnetic nanoparticles: feasibility, imaging, and threedimensional temperature distribution. Eur Urol. 2007;52:1653-62.

95. Yan S, Zhang D, Gu N, Zheng J, Ding A, Wang Z, Xing B, Ma M, Zhang Y. Therapeutic effect of Fe2O3 nanoparticles combined with magnetic fluid hyperthermia on cultured liver cancer cells and xenograft liver cancers. J Nanosci Nanotechnol. 2005;5:1185-92.

96. Sun C, Lee JS, Zhang M. Magnetic nanoparticles in MR imaging and drug delivery. Adv Drug Deliv Rev. 2008;60:1252-65.

97. Moroz P, Jones SK, Winter J, Gray BN. Targeting liver tumors with hyperthermia: ferromagnetic embolization in a rabbit liver tumor model. J Surg Oncol. 2001;78:22-9.

98. Lin J, Wang S, Huang P, Wang Z, Chen S, Niu G, Li W, He J, Cui D, Lu G. Photosensitizer-loaded gold vesicles with strong plasmonic coupling effect for imaging-guided photothermal/photodynamic therapy. ACS Nano. 2013;7:5320-9.

99. Han Y, An Y, Jia G, Wang X, He C, Ding Y, Tang Q. Theranostic micelles based on upconversion nanoparticles for dual-modality imaging and photodynamic therapy in hepatocellular carcinoma. Nanoscale. 2018;10:6511-23.

100. Skupin-Mrugalska P, Sobotta L, Warowicka A, Wereszczynska B, Zalewski T, Gierlich P, Jarek M, Nowaczyk G, Kempka M, Gapinski J. Theranostic liposomes as a bimodal carrier for magnetic resonance imaging contrast agent and photosensitizer. J Inorg Biochem. 2018;180:1-14.

101. Gahbauer R, Gupta N, Blue T, Goodman J, Barth R, Grecula J, Soloway A Sauerwein W, Wambersie A. Boron neutron capture therapy: principles and potential. In: Fast Neutrons and High-LET Particles in Cancer Therapy. Berlin, Heidelberg: Springer; 1998. p. 183-209. https://doi.org/10.1007/978-3-64278774-4_12.

102. Enger SA, Giusti V, Fortin M-A, Lundqvist H, af Rosenschöld PM. Dosimetry for gadolinium neutron capture therapy (GdNCT). Radiat Meas. 2013:59:233-40.

103. Salt C, Lennox AJ, Takagaki M, Maguire JA, Hosmane NS. Boron and gadolinium neutron capture therapy. Russ Chem Bull. 2004;53:1871-88.

104. Dewi N, Mi P, Yanagie H, Sakurai Y, Morishita Y, Yanagawa M, Nakagawa T, Shinohara A, Matsukawa T, Yokoyama K. In vivo evaluation of neutron capture therapy effectivity using calcium phosphate-based nanoparticles as Gd-DTPA delivery agent. J Cancer Res Clin Oncol. 2016;142:767-75.

105. Shikata F, Tokumitsu H, Ichikawa H, Fukumori Y. In vitro cellular accumulation of gadolinium incorporated into chitosan nanoparticles designed for neutron-capture therapy of cancer. Eur J Pharm Biopharm. 2002:53:57-63

106. Tokumitsu H, Hiratsuka J, Sakurai Y, Kobayashi T, Ichikawa H, Fukumori Y. Gadolinium neutron-capture therapy using novel gadopentetic acidchitosan complex nanoparticles: in vivo growth suppression of experimental melanoma solid tumor. Cancer Lett. 2000;150:177-82.

107. Tokumitsu H, Ichikawa H, Fukumori Y. Chitosan-gadopentetic acid complex nanoparticles for gadolinium neutron-capture therapy of cancer: preparation by novel emulsion-droplet coalescence technique and characterization. Pharm Res. 1999;16:1830-5.

108. Shih JLA, Brugger RM. Gadolinium as a neutron capture therapy agent. Med Phys. 1992;19:733-44

109. Balafar MA, Ramli AR, Saripan MI, Mashohor S. Review of brain MRI image segmentation methods. Artif Intell Rev. 2010;33:261-74.

110. Schmitz BL, Aschoff AJ, Hoffmann MH, Grön G. Advantages and pitfalls in $3 T$ MR brain imaging: a pictorial review. Am J Neuroradiol. 2005;26:2229-37.

111. Verbeeten KM, Hermann KL, Hasselqvist M, Lausten GS, Joergensen $P$, Jensen CM, Thomsen HS. The advantages of MRI in the detection of occult hip fractures. Eur Radiol. 2005;15:165-9.

112. Wang G, Yu H, De Man B. An outlook on x-ray CT research and development. Med Phys. 2008;35:1051-64

113. Fitzgerald R. Phase-sensitive x-ray imaging. Phys Today. 2000;53:23-6.

114. Pietrzyk U, Herholz K, Fink G, Jacobs A, Mielke R, Slansky I, Würker M, Heiss W-D. An interactive technique for three-dimensional image registration: validation for PET, SPECT, MRI and CT brain studies. J Nucl Med 1994:35:2011-8

115. Rahmim A, Zaidi H. PET versus SPECT: strengths, limitations and challenges. Nucl Med Commun. 2008:29:193-207.

116. Salonen JT, Salonen R. Ultrasound B-mode imaging in observational studies of atherosclerotic progression. Circulation. 1993;87:1156-65.

117. Van Montfoort JE, Stieger B, Meijer DK, Weinmann H-J, Meier PJ, Fattinger KE. Hepatic uptake of the magnetic resonance imaging contrast agent gadoxetate by the organic anion transporting polypeptide Oatp1. J Pharmacol Exp Ther. 1999;290:153-7.

118. Herborn CU, Honold E, Wolf M, Kemper J, Kinner S, Adam G, Barkhausen J. Clinical safety and diagnostic value of the gadolinium chelate gadoterate meglumine (Gd-DOTA). Investig Radiol. 2007:42:58-62.

119. Tanaka H, Tanigawa T, Suzuki M, Otsuka K, Inafuku S. Effects of MRI contrast agents (Omniscan ${ }^{\mathrm{TM}}$ ) on vestibular end organs. Acta Otolaryngol. 2010;130:17-24.

120. Kirchin MA, Pirovano GP, Spinazzi A. Gadobenate dimeglumine (Gd-BOPTA): an overview. Investig Radiol. 1998;33:798-809.

121. Nelson KL, Gifford LM, Lauber-Huber C, Gross CA, Lasser TA. Clinical safety of gadopentetate dimeglumine. Radiology. 1995;196:439-43.

122. Runge VM, Kirsch JE, Burke VJ, Price AC, Nelson KL, Thomas GS, Dean BL, Lee C. High-dose gadoteridol in MR imaging of intracranial neoplasms. J Magn Reson Imaging. 1992;2:9-18.

123. Kim RJ, Albert TS, Wible JH, Elliott MD, Allen JC, Lee JC, Parker M, Napoli A, Judd RM. Performance of delayed-enhancement magnetic resonance imaging with gadoversetamide contrast for the detection and assessment of myocardial infarction: an international, multicenter, double-blinded, randomized trial. Circulation. 2008;117:629-37.

124. Staks T, Schuhmann-Giampieri G, Frenzel T, Weinmann H-J, Lange L, Platzek J. Pharmacokinetics, dose proportionality, and tolerability of gadobutrol after single intravenous injection in healthy volunteers. Investig Radiol. 1994;29:709-15.

125. Jordan R, Mintz R. Fatal reaction to gadopentetate dimeglumine. Am J Roentgenol. 1995;164:743-4

126. Goyen M. Gadofosveset-enhanced magnetic resonance angiography. Vasc Health Risk Manag. 2008;4:1.

127. Hompland T, Ellingsen C, Rofstad EK. Preclinical evaluation of Gd-DTPA and gadomelitol as contrast agents in DCE-MRI of cervical carcinoma interstitial fluid pressure. BMC Cancer. 2012;12:544.

128. Bjørnerud A, Johansson LO, Ahlström H. Pre-clinical results with Clariscan $^{\mathrm{TM}}$ (NC100150 injection); experience from different disease models. MAGMA. 2001;12:99-103.

129. Clement O, Siauve N, Cuénod C-A, Frija G. Liver imaging with ferumoxides (Feridex): fundamentals, controversies, and practical aspects. Top Magn Reson Imaging. 1998;9:167-82.

130. Bonnemain B. Superparamagnetic agents in magnetic resonance imaging: physicochemical characteristics and clinical applications a review. J Drug Target. 1998:6:167-74

131. Sigal R, Vogl T, Casselman J, Moulin G, Veillon F, Hermans R, Dubrulle F, Viala J, Bosq J, Mack M. Lymph node metastases from head and neck squamous cell carcinoma: MR imaging with ultrasmall superparamagnetic iron oxide particles (Sinerem MR)-results of a phase-III multicenter clinical trial. Eur Radiol. 2002;12:1104-13.

132. Reimer P, Balzer T. Ferucarbotran (Resovist): a new clinically approved RES specific contrast agent for contrast-enhanced MRI of the liver: properties, clinical development, and applications. Eur Radiol. 2003;13:1266-76. 